\title{
Reliability of resistance/deformation during electrically-driven thermal cycles under stress on $\mathrm{Ni}_{25} \mathrm{Ti}_{50} \mathrm{Cu}_{25}$ melt spun ribbons
}

\author{
G. Gomarasca, G. Airoldi and A.V. Shelyakov ${ }^{1}$ \\ INFM, Dipartimento di Scienza dei Materiali, Università di Milano Bicocca, Via R. Cozzi 53, \\ 20125 Milano, Italy \\ ${ }^{1}$ Department of Solid State Physics, Moscow Engineering Physics Institute, \\ Kashirskoe Shosse 31, 115409 Moscow, Russia
}

\begin{abstract}
The use of shape memory alloys for sensing/actuating strictly relies on the possibility to easily relate the Electrical Resistance (ER) to strain ( $\varepsilon$ ).

Previous measurements of $\mathrm{ER}$ vs $\varepsilon$ on $\mathrm{Ni}_{25} \mathrm{Ti}_{50} \mathrm{Cu}_{25}$ ribbons detected during thermal cycling under a stress state have clearly shown that a linear relationship between ER and $\varepsilon$ can be obtained for an applied stress lower than $50 \mathrm{MPa}$. ER and $\varepsilon$ have been here investigated during repeated electrically driven thermal cycles under an applied stress either 50 or $100 \mathrm{MPa}$ on $\mathrm{Ni}_{25} \mathrm{Ti}_{50} \mathrm{Cu}_{25}$ melt spun ribbons up to 8000 electrically-driven cycles.

Small plastic deformation, with a typical figure of $\varepsilon_{\mathrm{P}} \sim 510^{-4}$ for $50 \mathrm{MPa}$ and $\varepsilon_{\mathrm{P}} \sim 110^{-3}$ for $100 \mathrm{MPa}$, is built in during cycling and levels after few thousand cycles. Under a stress of $100 \mathrm{MPa}$ specimens break after $2000-4000$ cycles. No broken specimen has been found even after 8000 cycles under $50 \mathrm{MPa}$ applied stress.

The hysteresis width of the ER- $\varepsilon$ curves modifies with cycling for both applied stresses.
\end{abstract}

\section{INTRODUCTION}

Several experimental investigations have already pointed out the interest to use the shape memory $\mathrm{Ni}_{25} \mathrm{Ti}_{50} \mathrm{Cu}_{25}$ alloy: the presence of one single martensitic transformation B2-B19 and the narrow hysteresis being the most appealing features [1].

Based on these premises the electrical transport properties as a function of deformation, under a constant stress state across the transformation range, has been shown to follow an almost linear relationship [2-4]: this feature can profitably be exploited in sensing/actuating on condition that reliability in repeated cycles can be guaranteed.

Author's previous results [5] have proved this is the case for an applied stress lower than $50 \mathrm{MPa}$. Interest in assessing the capability to sustain higher stress levels in repeated cycles has stimulated further investigations, here performed on $\mathrm{Ni}_{25} \mathrm{Ti}_{50} \mathrm{Cu}_{25}$ ribbons obtained by melt-spinning. Repeated electrically driven thermal cycles were performed, under a constant stress state either of $50 \mathrm{MPa}$ or $100 \mathrm{MPa}$ up to 8000 cycles.

Results obtained are contrasted with previous one and with literature.

\section{EXPERIMENTAL}

Two batches (named $\mathrm{A}$ and $\mathrm{B}$ ) of $\mathrm{Ni}_{25} \mathrm{Ti}_{50} \mathrm{Cu}_{25}$ melt spun ribbons (thickness $33.9 \pm 0.6 \mu \mathrm{m}$, width $1.69 \pm 0.03 \mathrm{~mm}$, gauge length in the order of $100 \mathrm{~mm}$ ), with small different composition, were investigated. The specimens were submitted to a final thermal treatment of $500{ }^{\circ} \mathrm{C}$ for $300 \mathrm{~s}$, under vacuum.

Differential Scanning Calorimetry (DSC) measurements in the temperature range $\left[0^{\circ} \mathrm{C}, 100^{\circ} \mathrm{C}\right]$, at $0.33^{\circ} \mathrm{C} / \mathrm{s}$ scan rate, were performed with a Perkin-Elmer DSC7 to check the transformation behaviour of heat treated specimens, either before or after cycling under a constant stress state. 
Current driven cycles under different constant applied stresses were preliminarily performed to check the start condition for the fatigue measurements: 50 and $100 \mathrm{MPa}$ applied stresses were chosen to perform repeated electrically driven cycles on the ribbons.

Finely tuneable weights provided a constant load on the sample as described in [3], while a LVDT-based extensometer measured the specimen change length. Special grips with water cooling circulation were used to fix a reliable thermal cycle. Electrical contacts were built in the mechanical grips; the current and tension terminals were kept separated to improve accuracy. Everything was sheltered from air draughts.

Electrical Resistance (ER) and deformation $(\varepsilon)$ were acquired as a function of current density (J) after each current rise of $2.5 \mathrm{~mA}$ on a tread of $300 \mathrm{~ms}$ long. The selected parameters guaranteed a thermal equilibrium with the surroundings. The constant load was applied at start in parent phase, at the maximum current value. Each cycle $(P \rightarrow M \rightarrow P)$ was performed in a typical current range of $[0.15 \mathrm{~A}, 0.65 \mathrm{~A}]$.

The deformation $(\varepsilon)$, the Normalised Electrical Resistance (NER), the Stress Assisted Two Way Memory Effect (SATWME) and the plastic deformation $\left(\varepsilon_{\mathrm{p}}\right)$ defined as :

$$
\begin{gathered}
\varepsilon=\left(\varepsilon(J)-\varepsilon\left(J_{\max }\right)\right) / \varepsilon\left(J_{\max }\right) \\
N E R=\left(\operatorname{ER}(J)-E R\left(J_{\text {max }}\right)\right) / E R\left(J_{\text {max }}\right) \\
\text { SATWME }=\varepsilon\left(J_{\text {min }}\right)-\varepsilon\left(J_{\text {max }}\right) \\
\varepsilon_{\mathrm{p}}(\text { cycle } n)=\varepsilon_{\mathrm{n}}\left(J_{\text {max }}\right)-\varepsilon_{1}\left(J_{\text {max }}\right)
\end{gathered}
$$

were deduced from acquired data.

\section{RESULTS}

The DSC scans related to the start state of the two investigated alloys are shown in figure 1 : for both a two step transformation is evident, with peak temperatures here indicated with $T$ and $T^{\prime}$. For the stock $B$ the two peaks are $6{ }^{\circ} \mathrm{C}$ separated in temperature on heating and $10^{\circ} \mathrm{C}$ on cooling. The two peaks separation is lower in A alloy. The small peaks at higher temperature, $T^{\prime}(M-P)$ and $T^{\prime}(P-M)$ do not apparently depend upon alloy composition. The peak transformation temperatures are given in table 1 .

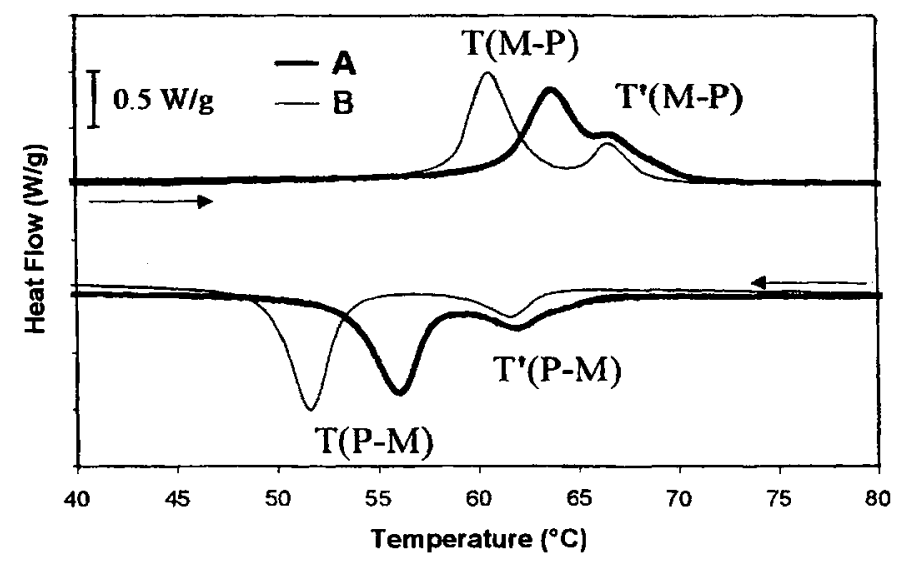

Figure 1: DSC scans on uncycled specimens.

Table 1: Peak transformation temperatures of uncycled specimens.

\begin{tabular}{|c|c|c|c|c|}
\hline Specimen & $\mathrm{T}(\mathrm{P}-\mathrm{M})\left(^{\circ} \mathrm{C}\right)$ & $\mathrm{T}^{\prime}(\mathrm{P}-\mathrm{M})\left({ }^{\circ} \mathrm{C}\right)$ & $\mathrm{T}(\mathrm{M}-\mathrm{P})\left({ }^{\circ} \mathrm{C}\right)$ & $\mathrm{T}^{\prime}(\mathrm{M}-\mathrm{P})\left(^{\circ} \mathrm{C}\right)$ \\
\hline $\mathrm{A}$ & 56.0 & 61.9 & 63.8 & 66.5 \\
\hline B & 51.6 & 61.6 & 60.6 & 66.5 \\
\hline
\end{tabular}

DSC scans on cycled specimens (after 3935 electrically driven cycles on stock A and 5230 on stock B)show a shift to higher temperature of T(M-P) peak in the first cycle. In the following thermal cycles the $\mathrm{T}(\mathrm{M}-\mathrm{P})$ peak recovers the original temperature (see fig. $2 \mathrm{a}, \mathrm{b}$ ). 

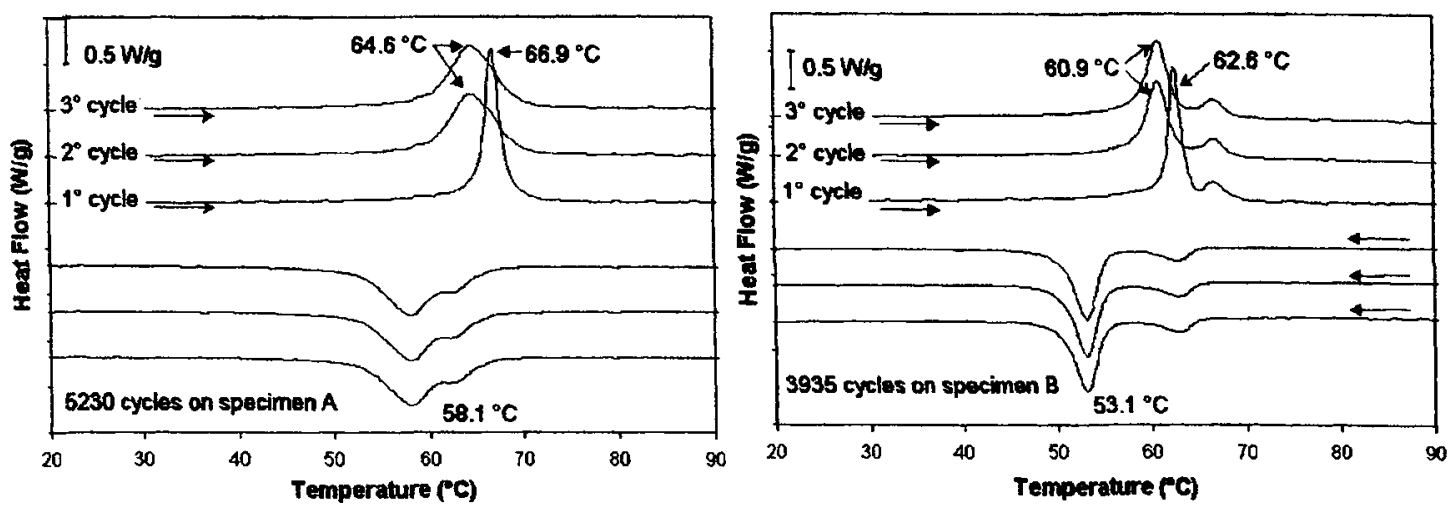

Figure 2a,b: DSC scans on cycled specimen under a stress of $50 \mathrm{MPa}$ : a) specimen A after 5230 cycles; b) specimen B after 3935 cycles. The scans are shifted on the heat flow scale for clarity.

Electrically driven cycles were performed at first in sequence under different applied constant stress state from 5 to $200 \mathrm{MPa}$. NER and $\varepsilon$ are plotted as a function of the current density for a typical specimen A (fig 3) and $B$ (fig 4) in the initial cycles at 5, 50 and $100 \mathrm{MPa}$ : the deduced NER vs $\varepsilon$ curves are also plotted in the same figures. The two step transformation exhibited on the DSC scans is not evident here, except for specimen B under the low stress of $5 \mathrm{MPa}$ (indicated by the arrow in the J-NER plane of figure 4): the two steps disappear for higher applied stresses.

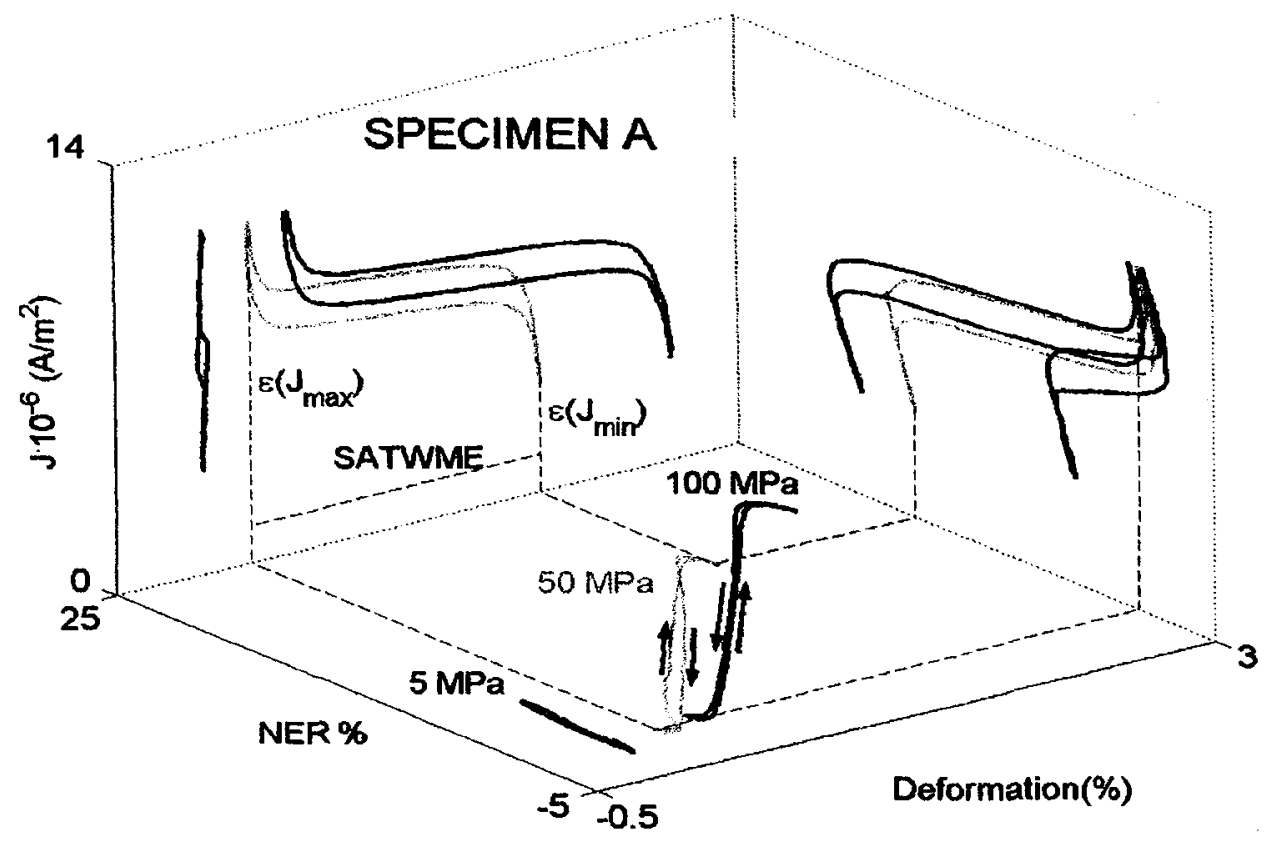

Figure 3: J-NER- $\varepsilon$ space: $\varepsilon$ vs J; NER vs J and NER vs $\varepsilon$ under 5, 50 and 100 MPa for A specimens. 


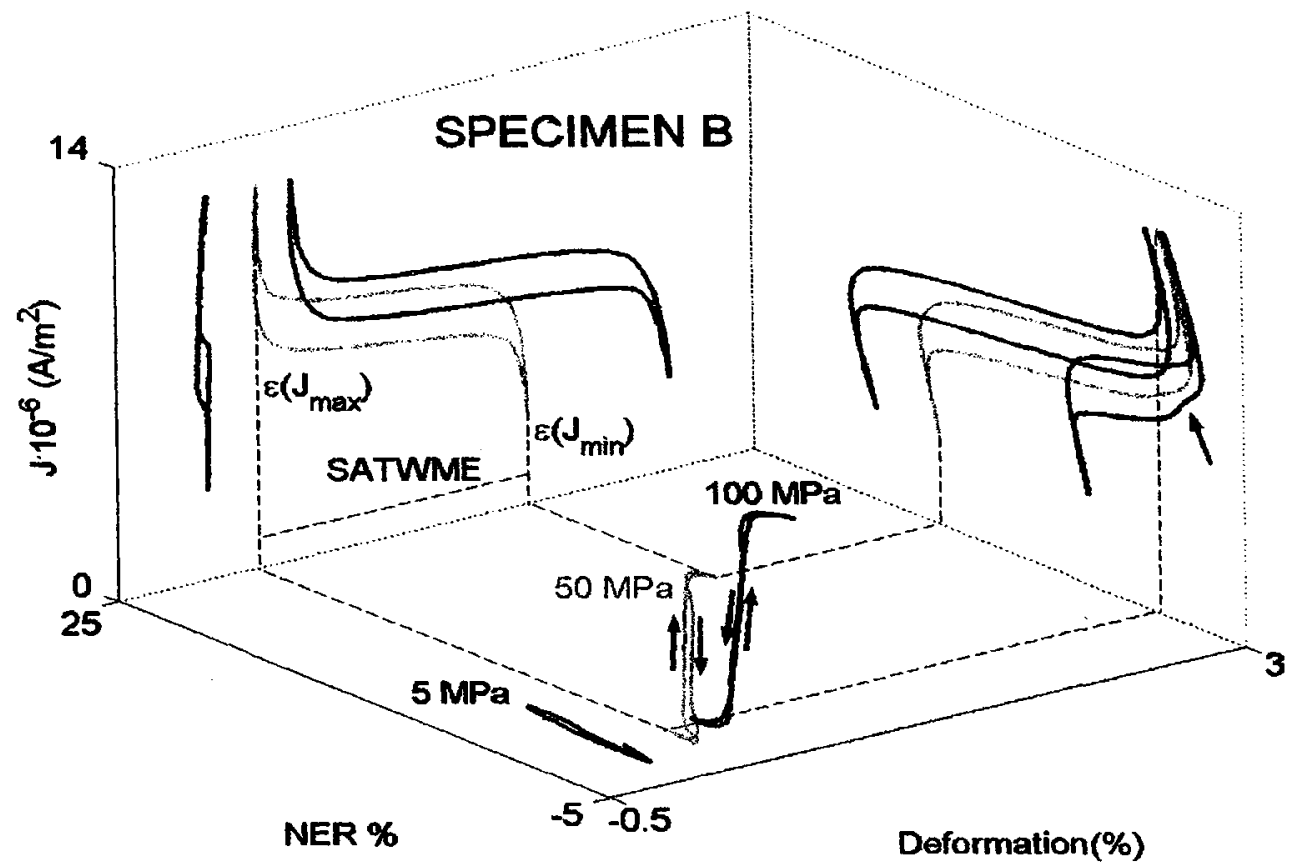

Figure 4: J-NER- $\varepsilon$ space: $\varepsilon$ vs $J$; NER vs $J$ and NER vs $\varepsilon$ under 5,50 and 100 MPa for B specimens.

The deformation values at the maximum and minimum current $\left(\varepsilon\left(J_{\max }\right)\right.$ and $\left.\varepsilon\left(J_{\min }\right)\right)$ and the SATWME, for the performed cycles on A and B specimen, are plotted in fig 5a,b. The specimens here shown cycled under $100 \mathrm{MPa}$ broke at 2263 (A) and 3715 cycles (B). Other tested specimens under the same conditions failed between 2000 and 4000 cycles. No broken specimen was found even after 8000 cycles for $50 \mathrm{MPa}$ applied stress.

The SATWME values generally increase with cycling under $1500-2000$ cycles: beyond they reach a somewhat constant value in the order of 1.5 and $2 \%$ (alloy B) for 50 and $100 \mathrm{MPa}$ respectively: slightly higher values are found for alloy $\mathrm{A}$

The total plastic deformation $\varepsilon_{\mathrm{P}}$, shown in fig $6 \mathrm{a}, \mathrm{b}$, increases more steeply under $100 \mathrm{MPa}$ reaching $0.1 \%$ respect to $\varepsilon_{\mathrm{P}} \sim 0.05 \%$ reached under $50 \mathrm{MPa}$. The corresponding values for specimen $\mathrm{B}$ are even lower.
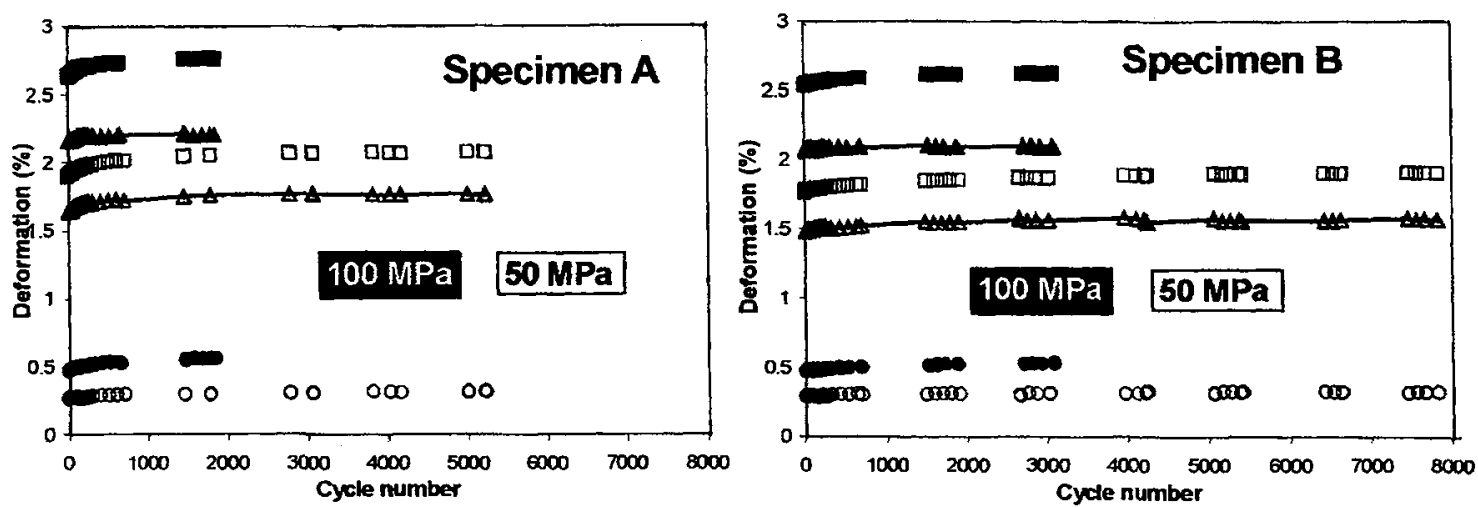

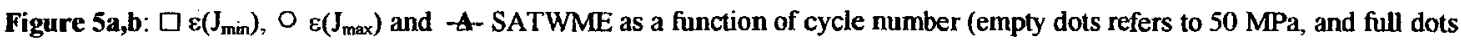
to $100 \mathrm{MPa}$ ): a) A alloy b) $\mathrm{B}$ alloy. 

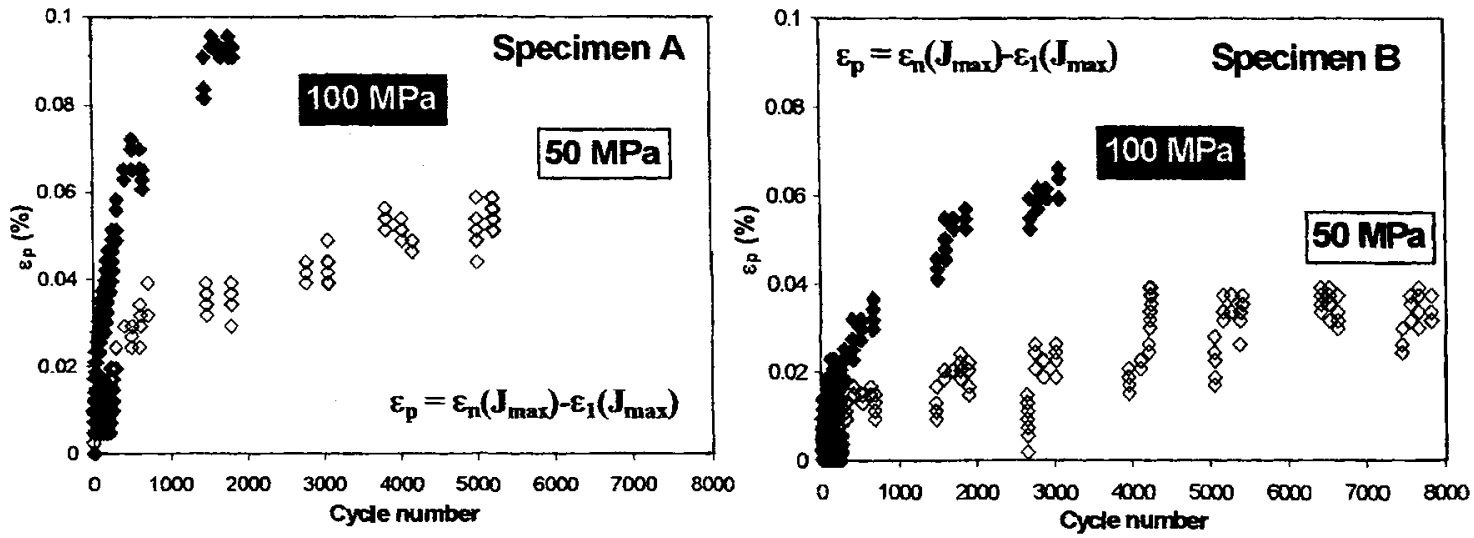

Figure 6a,b: Plastic deformation as a function of cycle number for $50 \mathrm{MPa}$ (empty dots) and $100 \mathrm{MPa}$ applied stress (full dots): a) A alloy; b) B alloy.

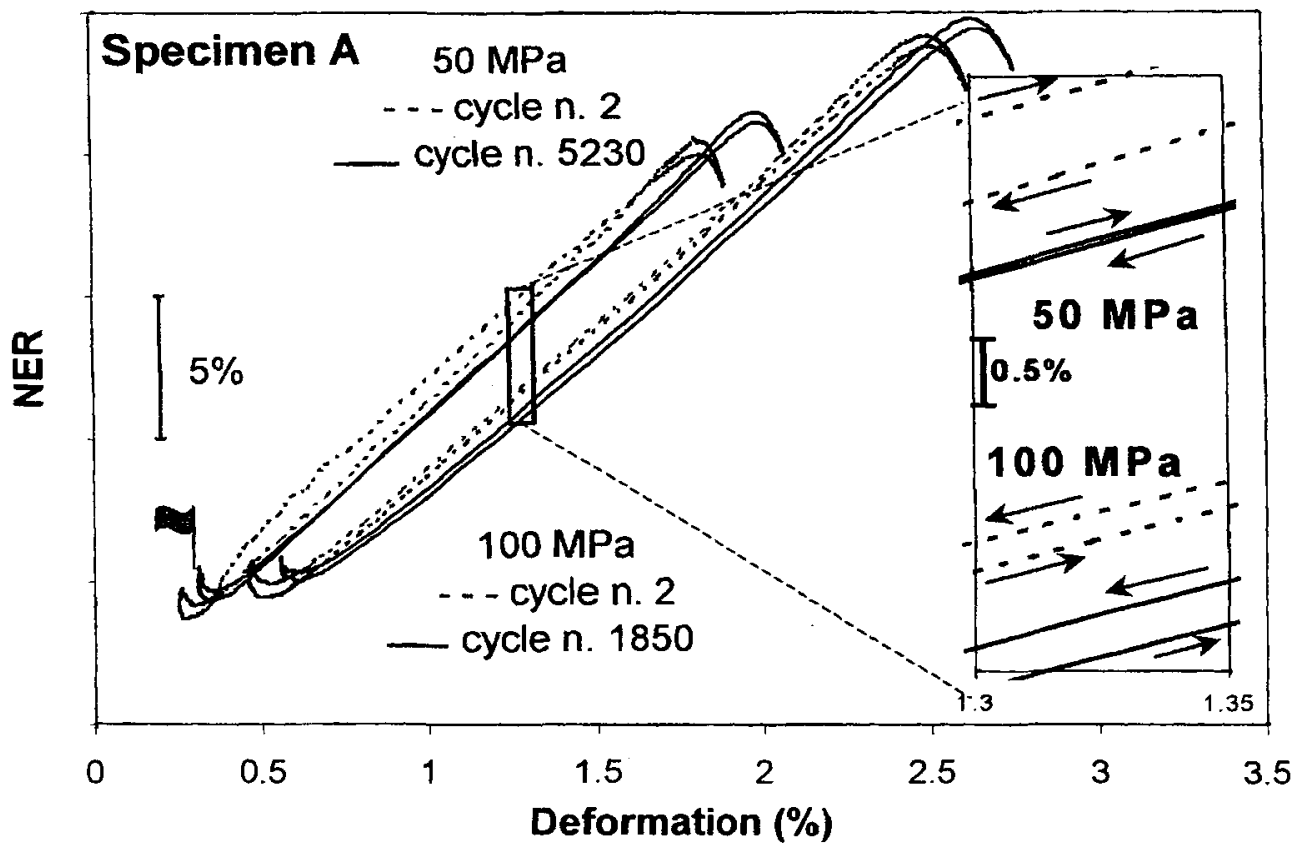

Figure 7: NER ys $\varepsilon$ during the first cycle (dashed line) and the last cycle (solid line) for a typical specimen A under 50 and 100 MPa (see text for explanation of details). The flag indicates the start point of the one curve. 


\section{DISCUSSION}

The origin of the second transformation ( $T^{\prime}$ ) shown on DSC scans, as discussed in another paper at this conference [6], is due to a thin surface layer present on the "free" surface of the ribbons. As clearly shown on fig. 2, T'(M-P) does not depend on cycling under stress, whilst $T(M-P)$ shifts to higher temperatures: that explains the evidence of the two step transformation found on cycling under $5 \mathrm{MPa}$ on NER vs $\mathrm{J}$ just for specimen B (see fig. 4). At higher stress the two step disappear due to the shift of the first transformation to higher temperatures.

For the test at $50 \mathrm{MPa}$ the total plastic deformation increase under two thousand cycles and levels on for a higher number of cycles. A similar trend was found for the higher investigated stress with maximum figures of $0.1 \%(100 \mathrm{MPa}$, alloy $\mathrm{A})$ and $0.5 \%$ (50 MPa, alloy $\mathrm{A})$. $\varepsilon_{\mathrm{p}}$ accumulated in $\mathrm{B}$ specimens is somewhat lower. The figures of $\varepsilon_{\mathrm{p}}$ are low compared to SATWME and for trained specimens $\varepsilon_{\mathrm{p}}$ does not modify: no drift of the curves NER vs $\varepsilon$ are found.

SATWME is in the order of 1.5 and $2 \%$ (alloy B) for 50 and $100 \mathrm{MPa}$ and slightly higher for alloy A: the values obtained for $\mathrm{Ni}_{25} \mathrm{Ti}_{50} \mathrm{Cu}_{25}$ are decidedly lower than the corresponding values found in $\mathrm{NiTi}$ for the same applied stress.

Some features of the hysteresis cycles deserve attention: in fig. 6 the NER vs $\varepsilon$ is shown during the first and the last of the performed cycles under either 50 or $100 \mathrm{MPa}$ for an A specimen. It can clearly be appreciated in the exploded view the evolution of the hysteresis cycle which narrows with cycling under the low stress and widens under the higher stress: in the first case a crossing point is present at the start of martensite oriented growth and at the end of the reorientation process. The crossing points disappear after long cycling: the disappearing of the crossing point can possibly be related to an incomplete reorientation reached in the first cycle, completed after thousands cycles.

For higher applied stress, the origin of the widening has not yet been explained

\section{CONCLUSION}

DSC results show the presence of a small transformation peak insensitive to cycling across the transformation, related to a thin layer on the "free surface" of the ribbons.

A low plastic strain is introduced with cycling for both investigated stress states which levels off after two thousand cycles.

The linear relationship ER vs $\varepsilon$ is retained almost all over the repeated cycles with hysteresis features which however change with applied stress as a function of cycling. Trained specimens, under $50 \mathrm{MPa}$, after some thousand cycles, show the narrowest hysteresis.

The widening of the hysteresis cycle under $100 \mathrm{MPa}$ has not yet received an explanation and deserve future investigations.

\section{Acknowledgements}

Research was supported by I.N.F.M. (Istituto Nazionale per la Fisica della Materia) here gratefully acknowledged.

\section{References}

1. N.M.Matveeva, Yu.K.Kovneristyi, Yu.A.Bykovskii, A.V.Shelyakov, O.V.Kostyanaya Izvestiya Akademyi Nauk SSSR. Metally, No. 4, 171-175, 1989

2. G.Airoldi, M.Pozzi, G.Riva, Mat.Res.Soc.Symp.Proc.459,459,1997

3. G.Airoldi, M.Pozzi, Trans.ASME J.of Engin.Mat. and Technol.121,(1999), 108

4. M.Pozzi, G.Airoldi, Mat.Sc.Eng. A273-275,300, 1999

5. Airoldi G., Gomarasca G., Omodei L., ${ }^{\text {st }}$ European Conf. on Shape Memory and Superelastic Technologies, Antwerp, 5-9 sept. 1999, B

6. P.Schloßmacher, H.Rosner, A.V.Shelyakov, G.Gomarasca, G.Airoldi, Esomat 2000 